\title{
PREDICTION OF THE LIFTOFF, BLOWOUT AND BLOWOFF STABILITY LIMITS OF PURE HYDROGEN AND HYDROGEN/HYDROCARBON MIXTURE JET FLAMES
}

\author{
Y. Wu ${ }^{1}$, Y. Lu ${ }^{1}$, I. S. Al-Rahbi, ${ }^{1}$ and G. T. Kalghatgi ${ }^{2}$ \\ ${ }^{1}$ Department of Chemical and Process Engineering, University of Sheffield, Sheffield S1 3JD, UK \\ ${ }^{2}$ Shell Global Solutions (UK), Cheshire Innovation Park, P.O. Box 1, Chester CH1 3SH, UK
}

\begin{abstract}
The paper presented experimental studies of the liftoff and blowout stability of pure hydrogen, hydrogen/propane and hydrogen/methane jet flames using a $2 \mathrm{~mm}$ burner. Carbon dioxide and Argon gas were also used in the study for the comparison with hydrocarbon fuel. Comparisons of the stability of $\mathrm{H}_{2} / \mathrm{C}_{3} \mathrm{H}_{8}, \mathrm{H}_{2} / \mathrm{CH}_{4}, \mathrm{H}_{2} / \mathrm{Ar}$ and $\mathrm{H}_{2} / \mathrm{CO}_{2}$ flames showed that $\mathrm{H}_{2} / \mathrm{C}_{3} \mathrm{H}_{8}$ produced the highest liftoff height and $\mathrm{H}_{2} / \mathrm{CH}_{4}$ required highest liftoff and blowoff velocities. The non-dimensional analysis of liftoff height approach was used to correlate liftoff data of $\mathrm{H}_{2}, \mathrm{H}_{2}-\mathrm{C}_{3} \mathrm{H}_{8}, \mathrm{H}_{2}-\mathrm{CO}_{2}, \mathrm{C}_{3} \mathrm{H}_{8}$ and $\mathrm{H}_{2}$-Ar jet flames tested in the $2 \mathrm{~mm}$ burner. The suitability of extending the empirical correlations based on hydrocarbon flames to both hydrogen and hydrogen/hydrocarbon flames was examined.
\end{abstract}

\subsection{INTRODUCTION}

The stabilization mechanisms of turbulent jet flames have been the topic of many papers and the most recent review was given by Peters [1]. It has emerged that the most successful theories to explain and predict the liftoff height location are the premixed flame propagation models[2-7] based on proposal by Vanquickenborne and van Tiggelen[2]. The importance of the isothermal mixing process of the jet was emphasised by Pitts [3-5]. The turbulent burning velocity has been one of the focused points for discussion using the premixed flame stabilization approach. Kalghatgi [6] assumed that the ratio of burning velocity to laminar burning velocity was proportional to the square root of the local turbulence Reynolds number based on the integral length scale. He successfully correlated the experimental data for $\mathrm{CH}_{4}, \mathrm{C}_{2} \mathrm{H}_{4}, \mathrm{C}_{3} \mathrm{H}_{8}$ and $\mathrm{H}_{2}$ into a single formula. More recent studies focused on the role of intermittence and large scale eddies and associated with premixed combustion by Broadwell et al. [7] and Burgess and Lawn [8]. Experimental studies of the large scale vortical structures in lifted flame were carried out by Schefer et al [9-10] using planar images of $\mathrm{CH}_{4}, \mathrm{CH}$ and temperature.

So far most jet flame researchers have used pure hydrocarbon fuels or fuels diluted with air or nitrogen. Empirical correlations were developed to predict flame stability limits for pure and inert gas diluted hydrocarbon fuels. As hydrogen is becoming an important part of energy sector, there is a need to study the stability characteristics of both hydrogen and hydrogen/hydrocarbon flames. Studies on stability of hydrogen/hydrocarbon blended fuels are scarce. Recently, the stability of hydrogen and natural gas blended fuel was discussed by Choudhuri and Gollahalli [11]. The effect of hydrogen addition into methane on the flame stability under fuel lean condition was studied by Schefer [12] using swirlstabilized flame. However it is not clear if the established premixed flame propagation models can be applied to jet flames of blended fuels. It is also necessary to examine the suitability of extending the empirical correlations based on hydrocarbon flames to both hydrogen and hydrogen/hydrocarbon flames. This work addressed these issues through a study of the stability of hydrogen flame with addition of propane, methane, carbon dioxide and argon.

\subsection{THE EXPERIMENTAL STUDY}

The experiments were carried out using a burner with a $2 \mathrm{~mm}$ inner diameter. The burner was fitted with flow settling chamber and flow straightening device. The gasses were introduced from compressed gas bottles through flow meters and were mixed before channeling into the settling chambers. The visual characteristics of the flames of pure hydrogen were very different from $\mathrm{H}_{2} / \mathrm{C}_{3} \mathrm{H}_{8}, \mathrm{H}_{2} / \mathrm{CH}_{4}$ and $\mathrm{H}_{2} / \mathrm{CO}_{2}$ 
flames. The pure hydrogen jet flames were almost invisible. $\mathrm{H}_{2} / \mathrm{CO}_{2}$ flames and $\mathrm{H}_{2} / \mathrm{CH}_{4}$ were in blue. The $\mathrm{H}_{2} / \mathrm{C}_{3} \mathrm{H}_{8}$ flames resembled characteristics of propane ones and appeared in blue in the base of the flame, but bright yellow in the main combustion zone. To visualize the flames and establish the lift off height of the flames, both schlieren technology and direct digital photography technology were used to capture the flame images of hydrogen, hydrogen/carbon dioxide flames. All flame images were captured using digital camera and processed using computer graphic packages.

\subsection{EXPERIMENTAL RESULTS}

\subsection{Stability of Pure Hydrogen Jet Flames}

Lifted hydrogen jet flames were produced in the $2 \mathrm{~mm}$ diameter burner. The liftoff velocity measured for pure hydrogen flame was $730 \mathrm{~m} / \mathrm{s}$. As shown in Figure 1, the liftoff height increased linearly with jet velocity. Three sets of experimental data from the current study using different image techniques were presented. Set $1 \& 2$ used the direct photography technique to determine the liftoff height, and set 3 used a Schlieren system to visualize the flame. The measured liftoff heights are in good agreement with the results of Kalghatgi [6] and Cheng and Chiou [14]. Blowout of pure hydrogen jet flame was not achieved in these experiments.

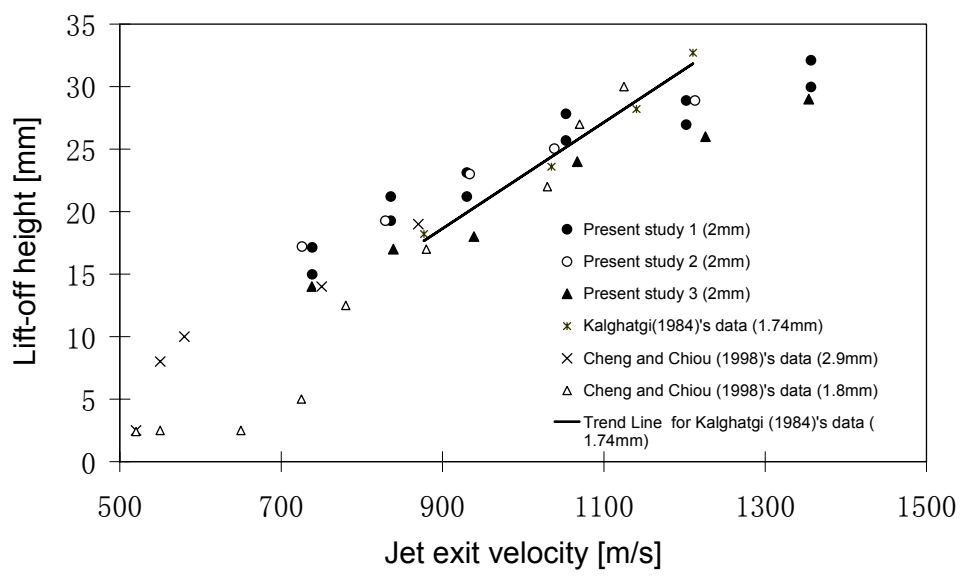

Figure 1. Comparison of experimental measured liftoff height of pure hydrogen jet flames against the jet velocity.

\subsection{Stability of H2-C3H8 Jet Flames}

Experimental test was carried out to study the effect of $\mathrm{C}_{3} \mathrm{H}_{8}$ addition on an initially attached and an initially lifted $\mathrm{H}_{2}$ jet flame. $\mathrm{C}_{3} \mathrm{H}_{8}$ addition to attached $\mathrm{H}_{2}$ flames always produced lifted flames, which were blown out at high jet velocities. Direct flame blowoff was not observed. Here blowoff refers to an attached jet flame extinguishing and liftoff is never observed. $\mathrm{C}_{3} \mathrm{H}_{8}$ addition to lifted $\mathrm{H}_{2}$ flames increased the liftoff height by nearly 2.6 times before blowout was observed. The blowout occurred at $\mathrm{C}_{3} \mathrm{H}_{8}$ concentration of around 4 to $5 \%$.

\subsection{Effect of $\mathrm{CO}_{2}$ and Ar Gas Addition on the Stability of $\mathrm{H}_{2}$ Jet Flames}

The effect of $\mathrm{CO}_{2}$ addition on the stability of an initially attached and also an initially lifted $\mathrm{H}_{2}$ flame was examined experimentally. The experimental results showed that when $\mathrm{CO}_{2}$ was added to an attached $\mathrm{H}_{2}$ flame, two flame stability regimes were identified. There is a critical $\mathrm{CO}_{2}$ concentration. If $\mathrm{CO}_{2}$ concentration was greater than $6.4 \%$, addition of $\mathrm{CO}_{2}$ produced a stable attached flame leading to direct blow off at high velocities. If $\mathrm{CO}_{2}$ concentration was less than $6.4 \%, \mathrm{CO}_{2}$ addition produced a lifted 
flame and then the flame was blown out at higher velocities.

Experiments were also were carried out to examine the effect of $\mathrm{CO}_{2}$ addition on lifted $\mathrm{H}_{2}$ flames. It was showed that the $\mathrm{CO}_{2}$ addition increased the liftoff height by nearly two times the initial liftoff height of pure $\mathrm{H}_{2}$ flames.

Tests were also carried out using argon for comparison with $\mathrm{CO}_{2}$. Argon behaved in a similar way to $\mathrm{CO}_{2}$ and required a slightly higher blow out velocity.

\subsection{Stability of $\mathrm{H}_{2}-\mathrm{CH}_{4}$ Jet Flames}

Test results demonstrated that effects of $\mathrm{CH}_{4}$ addition were different from $\mathrm{C}_{3} \mathrm{H}_{8}$ addition. Similar to the effect of $\mathrm{CO}_{2}$ addition, there were two flame stability regimes when $\mathrm{CH}_{4}$ was added into initial attached hydrogen jet flames. If the $\mathrm{CH}_{4}$ concentration is greater than $20 \%$, flame would remain attached until blowoff at high velocity. If the $\mathrm{CH}_{4}$ concentration is less than $20 \%, \mathrm{CH}_{4}$ addition to an initial attached hydrogen jet flame can produce lifted flame. However the blowout flame conditions were not obtained in present study.

\subsection{DISCUSSIONS}

\subsection{Liftoff Height}

Figure 2 shows a comparison of the liftoff height of $\mathrm{H}_{2} / \mathrm{C}_{3} \mathrm{H}_{8}, \mathrm{H}_{2} / \mathrm{CH}_{4}$ and $\mathrm{H}_{2} / \mathrm{CO}_{2}$ flames. The addition of the $\mathrm{CH}_{4}, \mathrm{CO}_{2}$ and $\mathrm{C}_{3} \mathrm{H}_{8}$ always increased the liftoff height of the initially lifted hydrogen diffusion flames. Addition of $\mathrm{C}_{3} \mathrm{H}_{8}$ produced the highest liftoff height. For the same jet exit velocity and same concentration of the diluents, the addition of $\mathrm{C}_{3} \mathrm{H}_{8}$ produced liftoff height around 15 to $30 \%$ higher than that of the addition of $\mathrm{CO}_{2}$. For the similar amount of diluent addition, at the same jet exit velocity, the addition of $\mathrm{CH}_{4}$ produced liftoff height lower than that of the addition of $\mathrm{C}_{3} \mathrm{H}_{8}$. At jet exit velocity higher than around $1000 \mathrm{~m} / \mathrm{s}$, the liftoff height of flames with $\mathrm{CH}_{4}$ addition are shown to be higher than that with $\mathrm{CO}_{2}$ addition. It might be predicted that at the high concentration of diluent (potentially be higher than $10 \%$ ), the addition of $\mathrm{CH}_{4}$ would produce higher lifted flames than that of $\mathrm{CO}_{2}$.

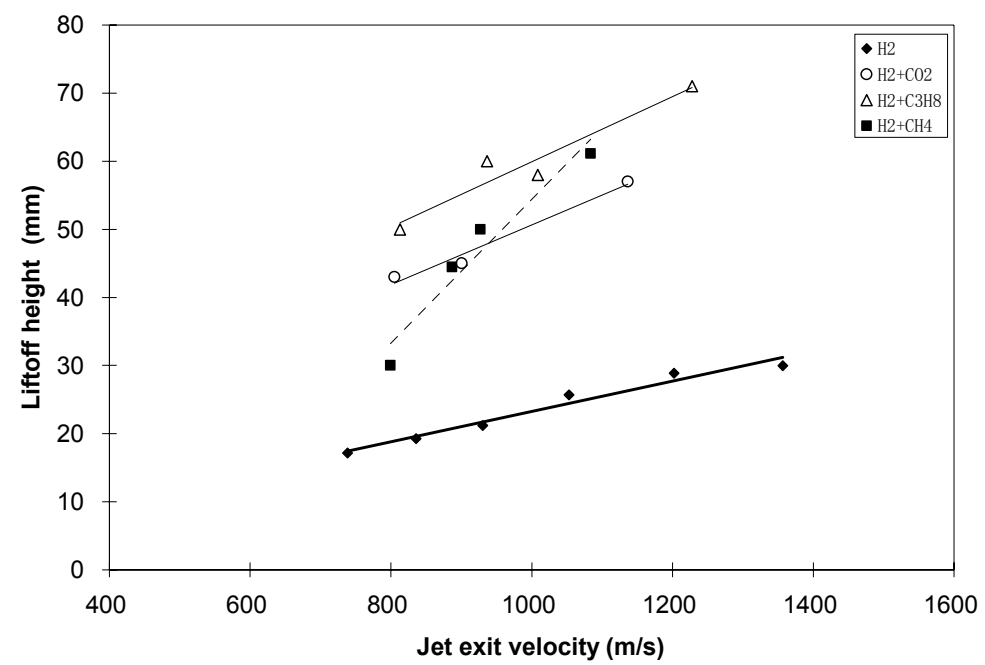

Figure 2. Comparison of the liftoff height of $\mathrm{H}_{2} / \mathrm{C}_{3} \mathrm{H}_{8}, \mathrm{H}_{2} / \mathrm{CH}_{4}$ and $\mathrm{H}_{2} / \mathrm{CO}_{2}$ flames.

\subsection{Liftoff Velocity}

A comparison of effect of propane addition and methane additions on liftoff velocity is shown in Figure 3. The results showed that for the same concentration, methane addition required much higher liftoff velocity than propane addition. 


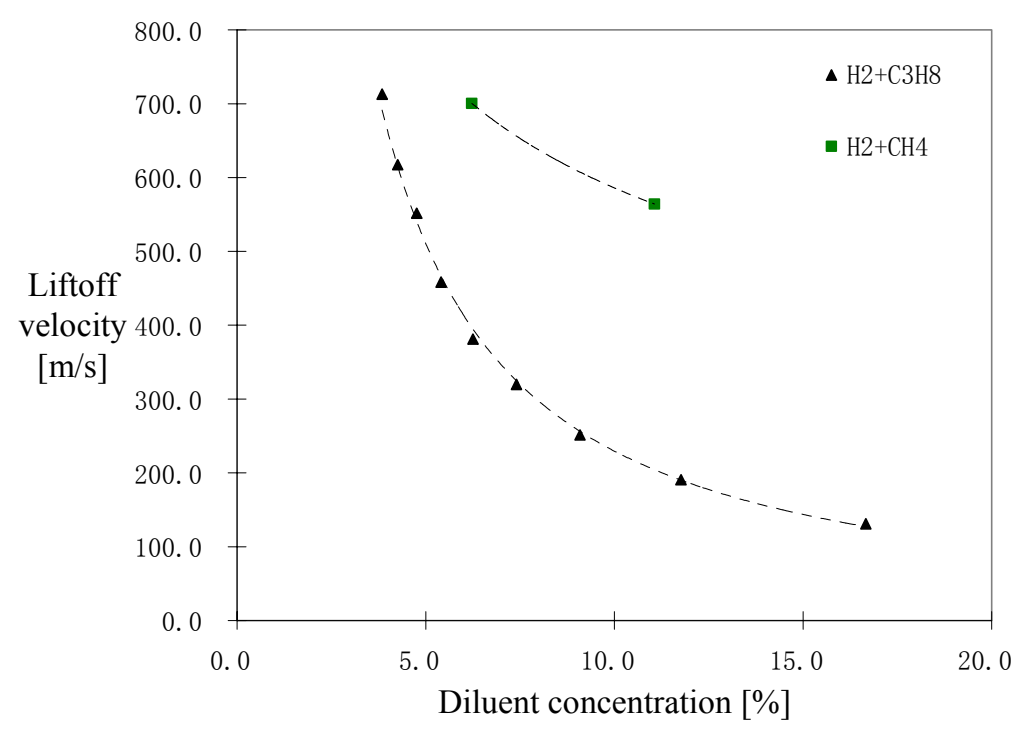

Figure 3. Comparison of liftoff velocity $\mathrm{H}_{2} / \mathrm{C}_{3} \mathrm{H}_{8}$ and $\mathrm{H}_{2} / \mathrm{CH}_{4}$ flames.

\subsection{Blowout and Blowoff Velocity}

Effects of $\mathrm{C}_{3} \mathrm{H}_{8}, \mathrm{CH}_{4}$ and $\mathrm{CO}_{2}$ additions on blowout or blowoff velocity were very different. Addition of $\mathrm{C}_{3} \mathrm{H}_{8}$ produced lifted flame and then blowout of the flame at higher velocity. Addition of $\mathrm{C}_{3} \mathrm{H}_{8}$ didn't cause direct blowoff. $\mathrm{CO}_{2}$ additions produced lifted flame in low concentration, but at high concentration, flame would remain attached until blowoff. Therefore for $\mathrm{H}_{2} / \mathrm{CO}_{2}$ flames both blowout and blowoff velocities were obtained. For $\mathrm{H}_{2} / \mathrm{CH}_{4}$ flames, only blowoff at high concentration was obtained. In Figure 4, the blowout and blowoff velocities are plotted against the addition concentration. It was shown that for the same jet velocity, $\mathrm{CH}_{4}$ required much higher concentration to produce blowoff than $\mathrm{CO}_{2}$. It was also showed that $\mathrm{C}_{3} \mathrm{H}_{8}$ requires higher velocity to blowout than $\mathrm{CO}_{2}$.

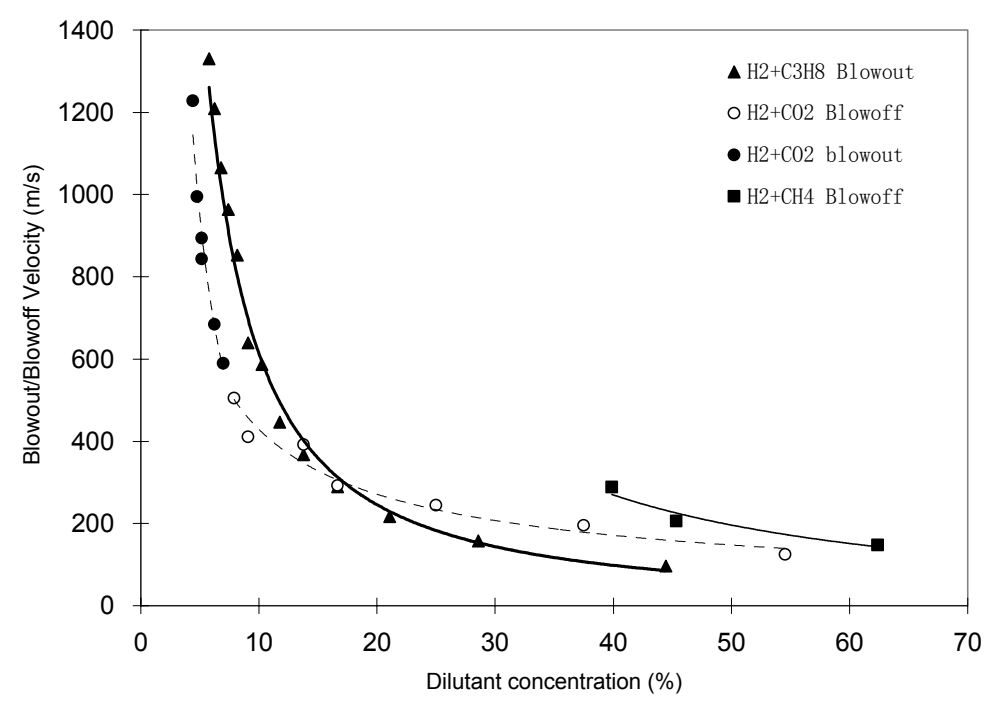

Figure 4. Comparison of blowout and blowoff velocity of $\mathrm{H}_{2} / \mathrm{C}_{3} \mathrm{H}_{8}, \mathrm{H}_{2} / \mathrm{CH}_{4}$ and $\mathrm{H}_{2} / \mathrm{CO}_{2}$ flames. 


\subsection{Laminar Burning Velocity}

Experimental studies of the laminar or fundamental flame velocity of hydrogen-air mixtures and diluted hydrogen-air mixtures have been reported in a number of studies [15-20]. The measured laminar burning velocity peaked at a rich mixture of equivalence ratio 1.8. However the reported value of the maximum laminar flame velocity of hydrogen air mixture varied from $250 \mathrm{~cm} / \mathrm{s}$ to $370 \mathrm{~cm} / \mathrm{s}$. The discrepancy was mainly due to whether the effect of stretch rate over the laminar flame velocity for the spherically expanding flames was taken into account. The flame velocity without inclusion of stretch effect was much higher than the unstretched flame velocity. A comparison of experimentally values of unstretched laminar flame velocity as a function of the equivalence ratio is given by Lamoureux, et al [15].

The effect of adding hydrocarbon fuel into the hydrogen-air mixture has been studied recently $[16,17,19$ and 20]. Leason [19] experimentally studied the effect of various additives, including hydrogen, on the burning velocity of propane-air mixture. Though this work covered a wide range of equivalence ratio, it was limited to hydrogen concentrations in the $\mathrm{H}_{2}-\mathrm{C}_{3} \mathrm{H}_{8}$ mixture of between 5 and $30 \%$. In our study, hydrogen was the dominant fuel with a small amount of propane addition. Some experimental data were obtained by Milton and Keck [17] on the burning speed of hydrogen/methane and hydrogen/propane mixtures at stoichiometric ratio. In the present study, the laminar burning velocity for hydrogen/propane was determined by plotting Milton and Keck's data and fitting a suitable equation.

The effect of $\mathrm{CO}_{2}$ dilution on the spherical flame Markestein number and unstretched laminar velocity was discussed by Lamoureux, et al [15]. However only limited laminar velocity data of lean hydrogen $/ \mathrm{CO}_{2}$ mixture were reported. In the present study, the laminar flame velocity for the hydrogen/ $\mathrm{CO}_{2}$ mixture is determined using Yumlu's equation [21].

A comparison of the effect of $\mathrm{CO}_{2}$ and $\mathrm{C}_{3} \mathrm{H}_{8}$ addition on the laminar flame velocity of $\mathrm{H}_{2}-\mathrm{CO}_{2}$ mixture and $\mathrm{H}_{2}-\mathrm{C}_{3} \mathrm{H}_{8}$ mixture is shown in Figure 5. It was clearly shown that the reduction in the burning velocity by adding propane was much more significant and greater than by adding $\mathrm{CO}_{2}$. For $\mathrm{H}_{2}-\mathrm{C}_{3} \mathrm{H}_{8}$ and $\mathrm{H}_{2}-\mathrm{CH}_{4}$ mixture, the laminar flame velocity reduced rapidly with the increasing concentration of propane/methane. The burning velocity of the mixture approached that of pure hydrocarbon fuel, when the hydrocarbon fuel addition was increased above $30 \%$. Hydrocarbon fuel appeared to be the dominant element governing the laminar burning velocity of the mixture. This can be attributed to the chemical kinetic mechanisms of the hydrocarbon-air reaction. Hydrocarbon fuel relies on reaction with $\mathrm{H}, \mathrm{O}$ and $\mathrm{OH}$ free radicals to break down to smaller hydrocarbon molecules and water. $\mathrm{H}, \mathrm{O}$ and $\mathrm{OH}$ free radicals are also of vital importance for the chain propagation of hydrogen. However, the reaction rate for hydrocarbon fuel with $\mathrm{H}, \mathrm{O}$ and $\mathrm{OH}$ free radicals is much faster than the $\mathrm{H}_{2}, \mathrm{H}, \mathrm{O}$ and $\mathrm{OH}$ chain reactions. Therefore the hydrocarbon fuel acted as sink for $\mathrm{H}, \mathrm{O}$ and $\mathrm{OH}$ free radicals and so dominates the reaction, which then hinders the $\mathrm{H}_{2} / \mathrm{O}_{2}$ reactions.

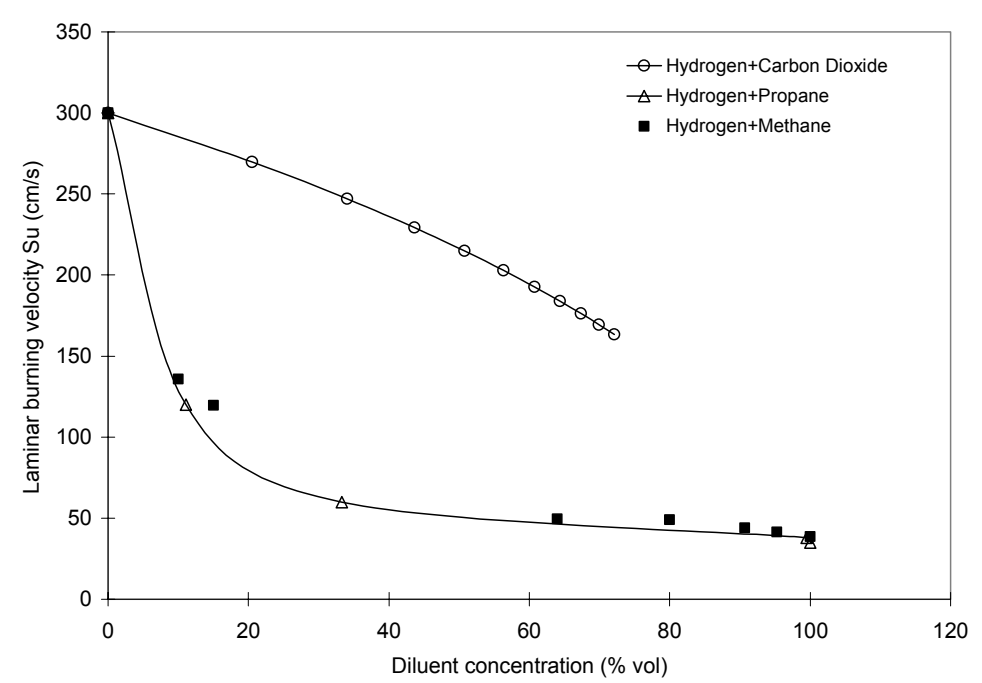

Figure 5. The laminar burning velocity of $\mathrm{H}_{2} / \mathrm{C}_{3} \mathrm{H}_{8}, \mathrm{H}_{2} / \mathrm{CH}_{4}$ and $\mathrm{H}_{2} / \mathrm{CO}_{2}$ flames. 


\subsection{Stoichiometric mass fraction}

The addition of $\mathrm{C}_{3} \mathrm{H}_{8}$ and $\mathrm{CH}_{4}$ also changes the mixture's stoichiometric fuel/ air ratio. The effect of hydrocarbon addition on the stoichiometric mass fraction is plotted in Figure $6 . \mathrm{C}_{3} \mathrm{H}_{8}$ addition increased the mixture's stoichiometric fuel/ air ratio significantly.

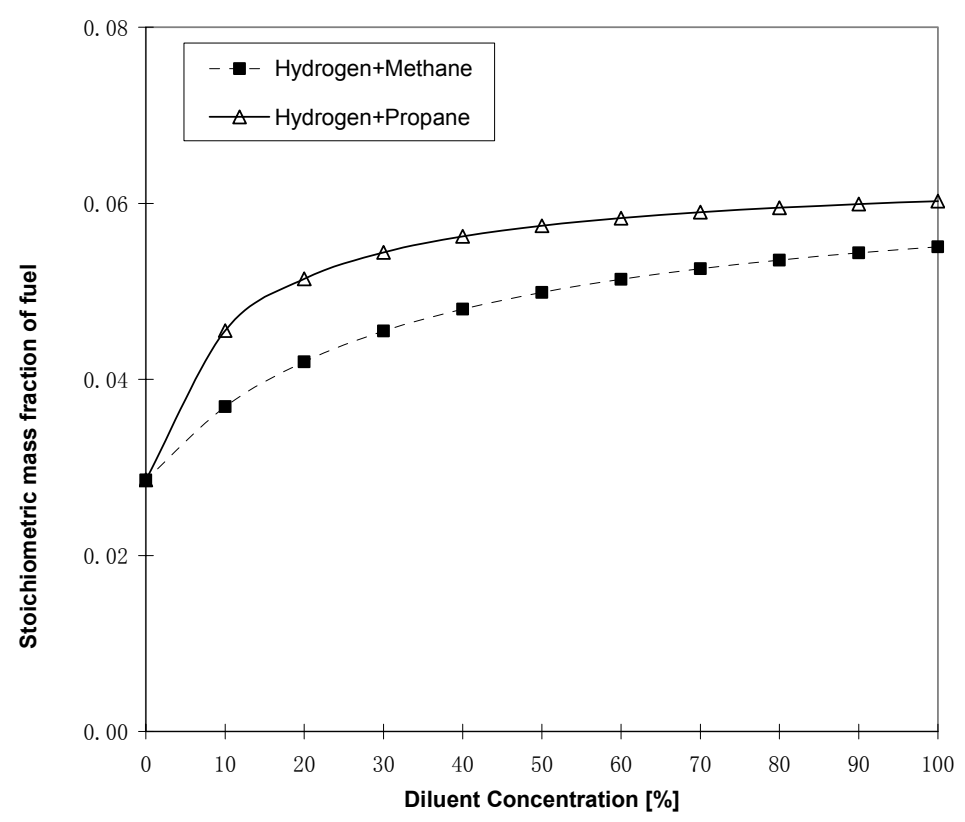

Figure 6 Comparison of stoichiometric mass fraction of fuel of the $\mathrm{H}_{2}-\mathrm{C}_{3} \mathrm{H}_{8}$ mixtures and $\mathrm{H}_{2}-\mathrm{CH}_{4}$ mixtures as a function of diluent concentration.

\subsection{Assessment of Empirical Correlations}

The non-dimensional analysis of liftoff height approach used by Kalghatgi [6] was adopted in present study to correlate liftoff data of $\mathrm{H}_{2}, \mathrm{H}_{2}-\mathrm{C}_{3} \mathrm{H}_{8}, \mathrm{H}_{2}-\mathrm{CO}_{2}, \mathrm{C}_{3} \mathrm{H}_{8}$ and $\mathrm{H}_{2}-\mathrm{Ar}$ jet flames tested in the $2 \mathrm{~mm}$ burner. The measured liftoff height was plotted against the jet exit velocity divided by the square of the maximum laminar flame velocity in Figure 7. It was shown that the hydrogen line was separate from the propane line and data from mixtures scattered in between. Considering Kalghatgi's non-dimensional analysis of liftoff height approach [6], Figure 8 shows the turbulence Reynolds number, Resu $=\frac{h s_{u}}{v_{j e t}}$, against the jet exit velocity divided by the burning velocity and modified by jet to air density ratio, where $h$ is flame liftoff height, $v_{j e t}$ is the viscosity and $s_{u}$ is the laminar flame velocity. The experimental data can be fitted into a single line with a slope of 48 , which is slightly lower than 50 obtained by Kalghatgi [6] for undiluted $\mathrm{CH}_{4}, \mathrm{C}_{2} \mathrm{H}_{4}, \mathrm{C}_{3} \mathrm{H}_{8}$ and $\mathrm{H}_{2}$ flames.

The comparison of measured hydrogen liftoff height to predictions from Kalghatgi's correlation[6] and Miake-Ley \& Hammer correlation [22] is shown in Figure 16. In the data analysis, the value of the laminar flame velocity for hydrogen was taken from the measurement of unstretched laminar flame velocity by Lamoureux et al [15]. $2.55 \mathrm{~m} / \mathrm{s}$ was used as the maximum laminar flame velocity for pure hydrogen. The comparison in Figure 9 showed that Kalghatgi's correlation predicted lower liftoff height for $\mathrm{H}_{2}$ flames and Miake-Ley \& Hammer correlation gave higher liftoff height for $\mathrm{H}_{2}$ flames. It is worth 
noting that the reported values of laminar flame velocity of hydrogen flames are scattered in the range $370 \mathrm{~cm} / \mathrm{s}$ to $250 \mathrm{~cm} / \mathrm{s}$. For hydrocarbon fuel, the maximum burning velocity occurred near the stoichiometric, therefore stabilization point of hydrocarbon fuel is stoichiometric. Unlike hydrocarbon fuel, hydrogen's maximum flame velocity occurs at the equivalence ratio 1.8. Recent experimental work of Tacke et al [23] showed that stabilization point of hydrogen flame was on the lean side not rich side. Further work with detailed concentration measurement is needed to clarify stabilization point of hydrogen flame and diluted hydrogen flames, therefore to allow a determination of suitable flame velocity values for the hydrogen or diluted hydrogen fuels in the empirical correlations of flame stability limits.

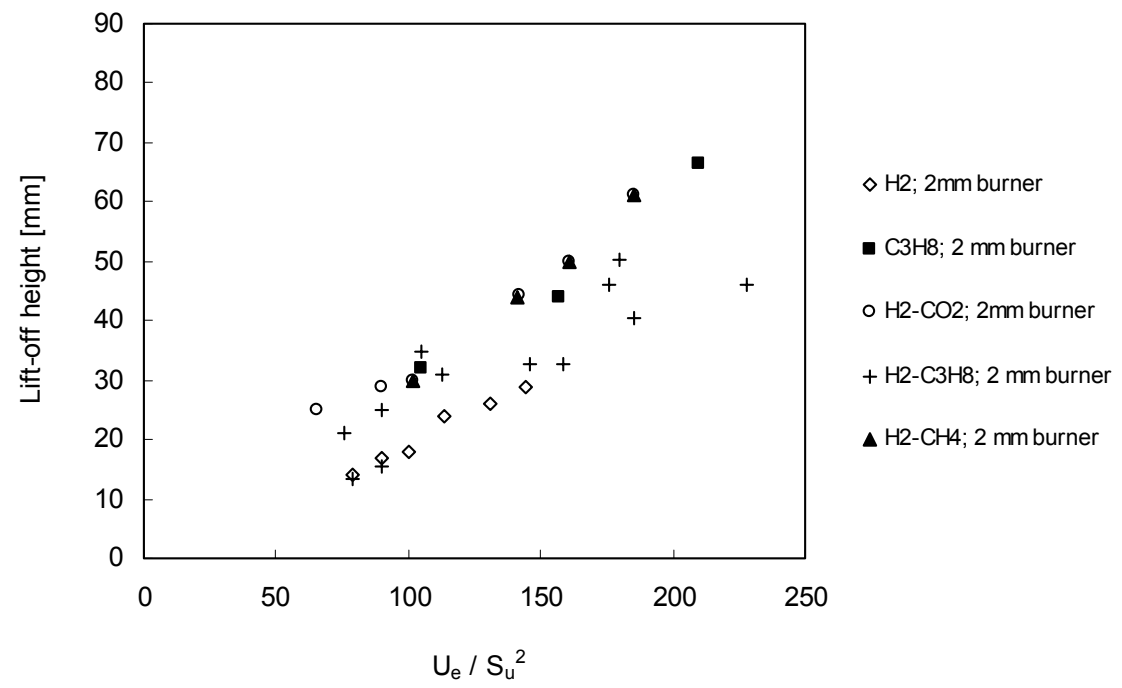

Figure 7: Variation of measured liftoff height with ratio of jet velocity to $\mathrm{Ue} /(\mathrm{Su})^{2}$.
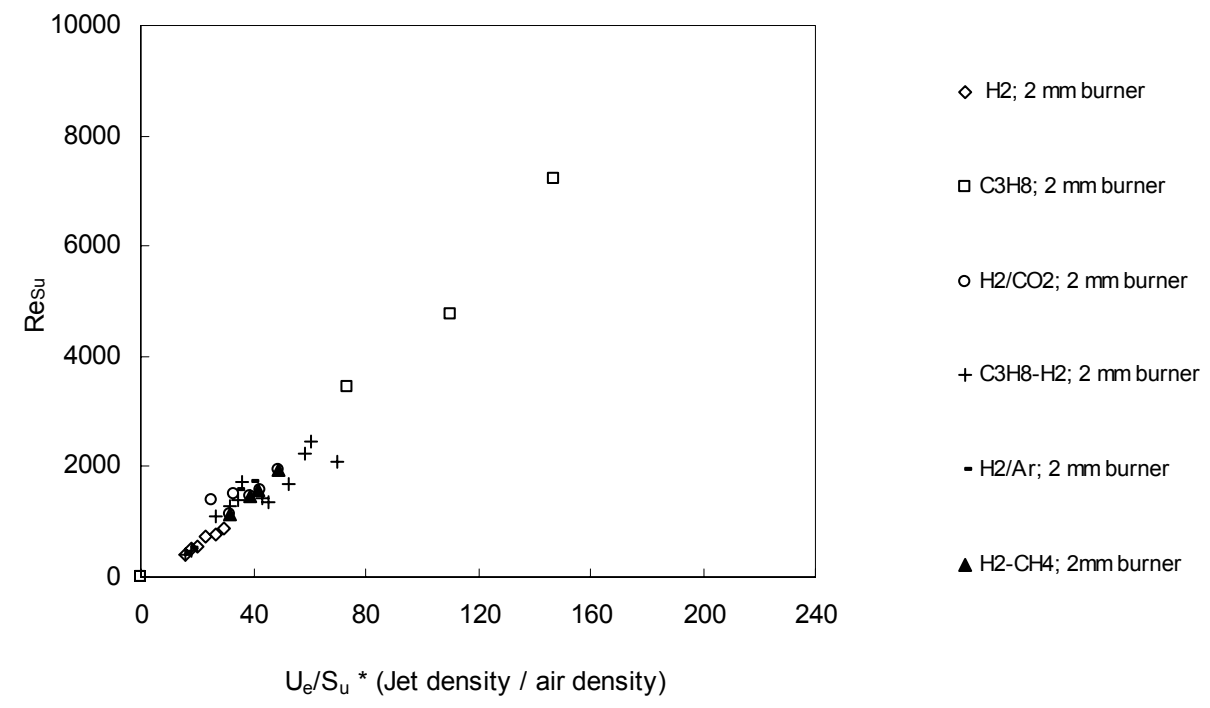

Figure 8: Non-dimensional analysis of liftoff height. 


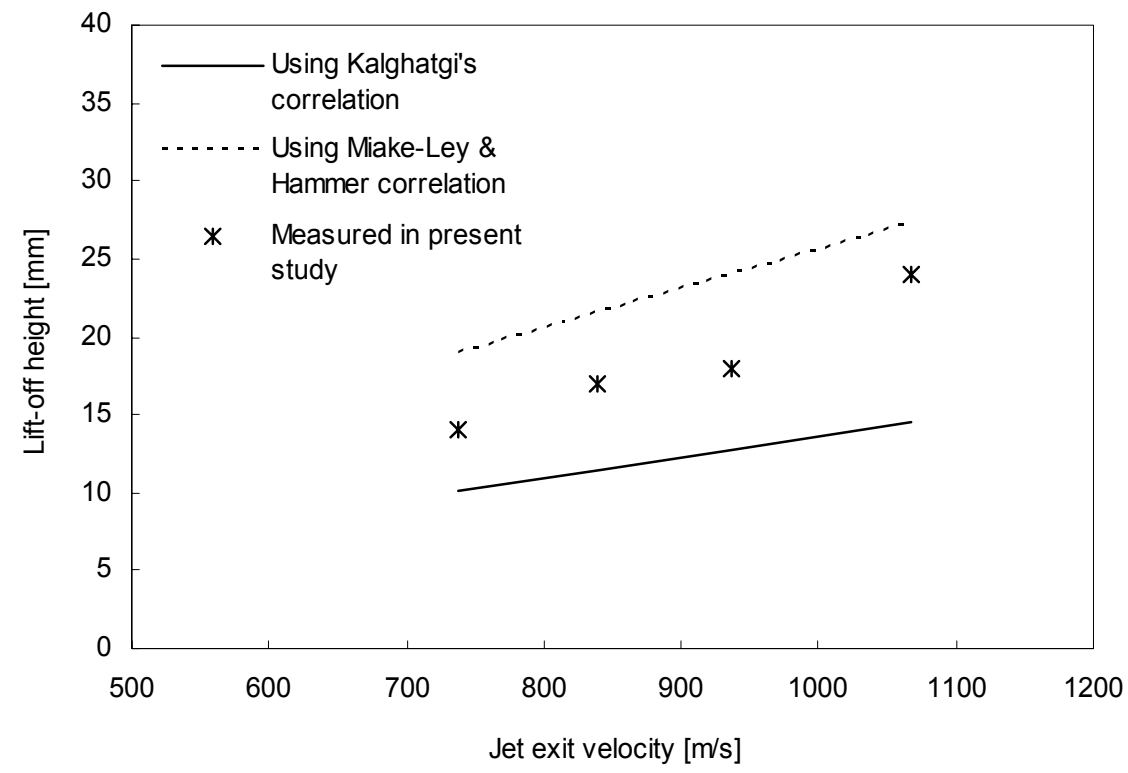

Figure 9: The comparison of measured hydrogen liftoff height to predictions from Kalghatgi's correlation and Miake-Ley \& Hammer correlation.

\subsection{CONCLUSIONS}

- The flame liftoff height of the pure $\mathrm{H}_{2}$ jet diffusion flame was found to increase with the jet velocity. Measured $\mathrm{H}_{2}$ liftoff heights agreed well with other published experimental data. Agreement with previously published correlations was found to depend on the value used for the maximum laminar burning velocity of $\mathrm{H}_{2}$. The reported values of laminar flame velocity of hydrogen flames are scattered in the range $370 \mathrm{~cm} / \mathrm{s}$ to $250 \mathrm{~cm} / \mathrm{s}$. The discrepancy was mainly due to whether and how the effect of stretch rate over the laminar flame velocity for the spherically expanding flames was taken into account.

- Comparisons of the stability of $\mathrm{H}_{2}-\mathrm{CO}_{2}, \mathrm{H}_{2}-\mathrm{C}_{3} \mathrm{H}_{8}$ and $\mathrm{H}_{2}-\mathrm{CH}_{4}$ flames showed that the addition of $\mathrm{C}_{3} \mathrm{H}_{8}$ to hydrogen required least liftoff velocity and produced highest liftoff height among three additive gases. $\mathrm{C}_{3} \mathrm{H}_{8}$ is most effective in producing lifted flames.

- The experimental results also showed that $\mathrm{C}_{3} \mathrm{H}_{8}$ addition is more effective in blowout of a hydrogen flame than $\mathrm{CO}_{2}$ addition. $\mathrm{CO}_{2}$ addition is more effective in blowoff attached hydrogen/additives flames than $\mathrm{CH}_{4}$ addition.

- The effects of methane on the hydrogen flame were different from the ones of propane and had similarities to the ones of carbon dioxide. At high concentration, direct blowoff of the methane/hydrogen was observed.

- The liftoff process of $\mathrm{H}_{2}-\mathrm{C}_{3} \mathrm{H}_{8}, \mathrm{H}_{2}-\mathrm{CH}_{4}$ and $\mathrm{H}_{2}-\mathrm{CO}_{2}$ jet flames was strongly influenced by the chemical kinetics. Hydrocarbon acted as a sink for the active radicals that are of importance in the combustion chemistry of $\mathrm{H}_{2}$. The hydrocarbon is the dominant element in determining the burning velocity of hydrogen hydrocarbon mixtures.

- Using non-dimensional analysis of liftoff height approach, the experimental data can be fitted into a single line with a slope of 48, which is slightly lower than 50 obtained by Kalghatgi [6] for undiluted $\mathrm{CH}_{4}, \mathrm{C}_{2} \mathrm{H}_{4}, \mathrm{C}_{3} \mathrm{H}_{8}$ and $\mathrm{H}_{2}$ flames. The uncertainty using this approach is the value of the maximum laminar flame velocity of hydrogen flames. 


\section{REFERENCES}

1. Peters N, Turbulent Combustion. Cambridge University Press, U.K., 2000.

2. Vanquickenborne V and Van Tiggelen A, Combustion and Flame, 10(1966) 59-69.

3. Pitts WM, Proc. Combust. Inst. 22 (1984) 253-360.

4. Pitts WM and Marto PJ, the second ASME-JSME Thermal Engineering Joint Conference, Honolulu, HI, March 22-27, 1987.

5. Pitts WM, Combustion and Flame, 76(1989)197-212 .

6. Kalghatgi GT., Combustion Science and Technology, 41 (1984)17-29.

7. Boadwell JE, Dahm JA and Mungal MG, Proc. Combust. Inst. 20 (1984) 303-310.

8. Burgess CP and Lawn CJ, Combustion and Flame, 119(199)95:108.

9. Schefer RW, Namazian M and Kelly J, Proc. Combust. Inst. 22(1988) 833-842.

10. Schefer RW and Goix PJ, Combustion and Flame, 112(1998)559-574.

11. Ahan R. Choudhuri and Gollahalli SR, AIAA Journal of Propulsion and Power, 19(2003) 220-225.

12. Schefer RW, International Journal of Hydrogen Energy, 28(10)(2003)1131-1141.

13. Fu S and Wu Y., Optical Engineering, Vol 40 Part 8 (August 2001)1661-1666.

14. Cheng TS and Chiou CR, 1998, Combustion Science and Technology, 136(1-6), 81-94.

15. Lamoureux, N, Djebailli-Chaumeix, N and Paillard, C.-E., Experimental Thermal and Fluid Science 27(2003) 385-393.

16. Huang, Z., Zhang, Y., Zengg, K., Liu, Bing, wang, Q. and Jiang, D., Combustion and Flame 146 (2006)302-311.

17. Ilbas, M., Crayford, A. P., Yilmaz, Ï., Bown, P. J. and Syred, N., International Journal of Hydrogen Energy 31 (2006) 1768-1779.

18. Liu, D.D.S. and MacFarlane, R., Combustion and Flame 49 (1983) 59-71.

19. Leason BD, Proc. Combust. Inst. 4(1952) 396-375.

20. Milton BE and Keck JC, , Combustion and Flame, 58 (1984) 13-22.

21. Yumlu VS, , Combustion and Flame, 12 (1968) 14-18.

22. Miake-Lye, R. C. and Hammer, J. A., Proc. of Combust. Inst, 22 (1988) 817-824.

23. Tacke MM, Geyer D, Hassel EP and Janicka J, Proc. Combust. Inst. 27 (1998) 1157-1165. 